\title{
O PROGRAMA INSTITUCIONAL DE BOLSAS DE INICIAÇÃO CIENTÍFICA PARA O ENSINO MÉDIO (PIBIC-EM): a política pública, a ciência e a cidadania
}

\author{
Larissa Reducino Silva21 \\ Ana Elisa Spaolonzi Queiroz Assis22
}

\begin{abstract}
RESUMO
Por meio do presente artigo, socializamos resultado de pesquisa cujo objetivo foi o de analisar a organização do Programa Institucional de Bolsas de Iniciação Científica para o Ensino Médio (PIBIC-EM) na Universidade Estadual de Campinas (UNICAMP) e a sua contribuição para a formação crítica dos estudantes do nível médio das escolas públicas no que diz respeito à ciência e a cidadania. A pesquisa, de caráter exploratório, foi realizada por meio de análise bibliográfica e documental - valendo-se dos materiais produzidos nos projetos desenvolvidos no Laboratório de Políticas Públicas e Planejamento Educacional (LaPPlanE) discutindo o programa e a sua contribuição para a efetivação de um diálogo entre a Educação Básica e o Ensino Superior. O texto introduz o contexto nacional e local do Programa, para então apresentar os conceitos de ciência e de cidadania assumidos na pesquisa, bem como as atividades desenvolvidas nos projetos, e a partir daí estabelece uma relação dialógica entre essas atividades e a abordagem teórica, finalizando com algumas considerações vinculadas aos resultados da pesquisa, dos quais podemos destacar mudança significativa na forma como os alunos bolsistas entendem a ciência e se reconhecem como sujeitos de direito.
\end{abstract}

Palavras-chave: Iniciação Científica. Ensino Médio. Cidadania.

\section{THE INSTITUTIONAL PROGRAM OF SCIENTIFIC INITIATION GRANT FOR HIGH SCHOOL (PIBIC-EM): the public policy, the science and the citizenship}

\begin{abstract}
Through this article, we socialize a research result whose aim was to analyze the organization of the Institutional Program of Scientific Initiation Grants for High School (PIBIC-EM) at the State University of Campinas (UNICAMP) and its contribution to the critical formation of public high school students in science and citizenship. The research, which was explanatory and done with bibliographical and documentary analysis, using the materials produced in the projects developed in the Laboratory of Public Policies and Educational Planning (LaPPlanE) discussed the program and its

${ }^{21}$ Graduanda do Curso de Pedagogia da Universidade Estadual de Campinas - UNICAMP. E-mail: lari_reducino@live.com

22 Doutora em Educação. Docente da Faculdade de Educação da Universidade Estadual de Campinas -UNICAMP. Coordenadora Associada do Curso de Pedagogia (gestão 20162017).E-mail: anasqa@unicamp.br
\end{abstract}


contribution to a dialogue between Basic Education and Higher Education. The text introduces the national and local context of the Program, to present the concepts of science and citizenship assumed in the research, as well as the activities developed in the projects, to establish a dialogical relationship between these activities and the theoretical approach. At the end, there are some considerations related to the results of the research, from which we can highlight a significant change in the way grantees understand science and recognize themselves as subjects of right.

Keywords: Scientific Research Iniciation. High School. Citizenship.

\section{INTRODUÇÃO}

Em 2003 o Conselho Nacional de Desenvolvimento Científico e Tecnológico (CNPq) ampliou o fomento de bolsas de iniciação científica para os estudantes da Educação Básica criando a Iniciação Científica Júnior (ICJ), normatizada pela Resolução Normativa (RN) 017/2006, que tem como objetivo o desenvolvimento de projetos de educação científica para os estudantes do ensino fundamental, médio e profissional das redes públicas de ensino. A proposta apresentada pretende incentivar e possibilitar a participação dos estudantes da educação básica nas atividades de pesquisa científica ou tecnológica orientadas por pesquisadores das instituições de ensino superior ou centros de pesquisa (CNPq, 2006).

O CNPa promove quotas de bolsas, para tal modalidade de iniciação científica, às entidades estaduais de fomento à pesquisa (Fundações de Amparo à Pesquisa ou Secretarias Estaduais) e "outras instituições, doravante denominadas entidades parceiras, por meio de Acordo de Cooperação Técnica, sem repasse de recursos, ou por Convênio, com repasse" (CNPq, $2006 \mathrm{~s} / \mathrm{n}$ ).

As instituições que tiverem interesse em operacionalizar a ICJ devem, preferencialmente, desenvolver atividades de pesquisa junto ao PIBIC e/ou ao Programa Institucional de Bolsas de Iniciação em Desenvolvimento Tecnológico e Inovação23 (PIBITI), como também dispor de infraestrutura

23 O Programa Institucional de Bolsas de Iniciação em Desenvolvimento Tecnológico e Inovação (PIBITI) é uma das modalidades de bolsas oferecidas pelo CNPq que tem por finalidade estimular estudantes do ensino técnico e superior ao desenvolvimento e transferência de novas tecnologias e inovação. 
adequada e disponibilizar, quando necessário, transporte e alimentação aos bolsistas responsabilizando-se pela segurança e integridade física e mental dos estudantes.

Como requisitos e condições a RN 017/2006 institui que os estudantes interessados no Programa devem estar regularmente matriculados no ensino fundamental, médio ou profissional de escolas públicas e possuírem frequência mínima de $80 \%$ (oitenta por cento). Os estudantes não podem estar vinculados ao mercado de trabalho e devem apresentar o histórico escolar (item 5.5.1 CNPq, $2006 \mathrm{~s} / \mathrm{n}$ ).

No contrato de iniciação científica o estudante assume os seguintes compromissos:

\footnotetext{
5.7 Implementação da Bolsa [...]

5.7.2 No contrato, deverão ser assumidos, fundamentalmente, os seguintes compromissos: [...]

5.7.2.2 Pelo estudante:

a) executar o plano de atividades com dedicação mínima de oito horas semanais;

b) elaborar relatório de suas atividades semestralmente, e ao final de sua participação;

c) apresentar os resultados parciais e finais da atividade, sob forma de painel ou exposição oral, acompanhados de relatório, nos encontros de iniciação científica e tecnológica promovidos pela instituição;

d) estar matriculado em escola pública de nível fundamental, médio ou profissional;

e) estar desvinculado do mercado de trabalho (CNPq, $2006 \mathrm{~s} / \mathrm{n}$ ).
}

O acompanhamento e a avaliação do estudante, enquanto bolsista de iniciação científica, é feita por meio de relatórios individuais, acompanhados do parecer do pesquisador orientador, e da participação dos estudantes nos eventos acadêmicos previstos (item 5.8, CNPq, 2006 s/n).

Como disposições finais, o CNPq orienta que haja participação dos professores do ensino fundamental, médio ou profissional na execução do plano de trabalho dos bolsistas sob orientação dos pesquisadores, incentivando o diálogo entre a Educação Básica e o Ensino Superior (item 5.10, CNPq, $2006 \mathrm{~s} / \mathrm{n})$. 
Atualmente o CNPq oferece três modalidades de bolsas de iniciação científica para a Educação Básica, a saber: Programa de Iniciação Científica Júnior (PIC Jr), instituído em 2003; Programa de Iniciação Científica da Olimpíada Brasileira de Matemática das Escolas Públicas (PIC-OBMEP), criado em 2006; e o Programa Institucional de Bolsas de Iniciação Científica para o Ensino Médio (PIBIC-EM), instituído em 2010.

O PIBIC-EM, objeto principal da pesquisa aqui apresentada, possui os mesmos objetivos da ICJ, porém, exclusivamente para os estudantes do ensino médio da rede pública.

Na Universidade Estadual de Campinas (UNICAMP) a ICJ foi instituída em 21/12/2007, pelo Processo CNPq n 610057/2007-3 (PRÓ-REITORIA DE PESQUISA DA UNICAMP, 2016b), com o apoio do CNPq no oferecimento de bolsas. Em maio de 2008 a Universidade iniciou as suas atividades com 0 Programa de Iniciação Científica Junior (PIC Jr) com 119 alunos selecionados de um grupo de 488 provenientes de 43 escolas públicas das cidades de Campinas (Diretoria de Ensino Região Leste e Oeste - Jaguariúna, Valinhos e Vinhedo), Limeira e Piracicaba. Neste mesmo ano, os estudantes foram distribuídos nos 50 projetos de pesquisa de docentes e pesquisadores das áreas de humanas, exatas, tecnológicas e biomédicas (PRÓ-REITORIA DE PESQUISA DA UNICAMP, 2016b).

No segundo ano do programa na UNICAMP, em 2009, foram 750 estudantes inscritos provenientes de 79 escolas. No total foram selecionados 144 alunos, inseridos nos 54 projetos submetidos à Pró-Reitoria de Pesquisa (PRP/UNICAMP). Com a demanda crescente pela IC-Jr a PRP passou a incentivar os professores orientadores com o auxílio financeiro no valor de $R \$ 3.000,00^{24}$ (três mil reais) para custeio das atividades nos laboratórios de pesquisa envolvidos no programa (PRÓ-REITORIA DE PESQUISA DA UNICAMP, 2016b).

\footnotetext{
24 Desde 2015 o auxílio financeiro passou a ser de $R \$ 4.000,00$ (quatro mil reais), quando o projeto acolhe no mínimo três bolsistas, na rubrica de material de consumo nacional ou prestação de serviços.
} 
Em 2010 o número de projetos apresentados pelos docentes da Universidade aumentou $68 \%$ em relação ao ano inicial do programa, com isso a PRP/UNICAMP acresceu com recursos próprios mais 30 bolsas de estudos às outras 150 da quota do CNPq. Neste mesmo ano, com o Edital do PIBIC-EM, a PRP/UNICAMP foi contemplada com 150 bolsas do Programa. Com isso, a UNICAMP passou a contar com 300 bolsas de iniciação científica para os programas voltados para os estudantes do nível médio das escolas públicas (PRÓ-REITORIA DE PESQUISA DA UNICAMP, 2016b).

A nova cota de bolsas do CNPq teria vigência a partir de 1 de outubro de 2010 até 30 de setembro de 2011, isso provocou um descompasso entre o calendário do PIC Jr e do PIBIC-EM. Para conciliar os dois calendários, com autorização do CNPq, os dois programas foram iniciados em agosto de 2011 com encerramento previsto para janeiro de 2013. Neste período de adaptação, o número de alunos dobrou, em comparação ao ano de 2009, e o número de projetos se manteve, porém, eles foram melhor distribuídos entre as áreas do conhecimento (PRÓREITORIA DE PESQUISA DA UNICAMP, 2016b).

Em 2013, com o fim do Processo CNPq $n^{\circ}$ 610057/2007-3 houve a diminuição de 150 bolsas de ICJ, e para evitar prejuízos aos estudantes a PRP assumiu a continuidade destas bolsas com recursos próprios da Universidade (PRÓ-REITORIA DE PESQUISA DA UNICAMP, 2016b).

Para a cota de 2014 e 2015 o programa concedeu na UNICAMP 140 bolsas por meio do Edital PIBIC-EM/CNPq e outras 160 por meio de recursos próprios. Já para a cota de 2016 - 2017 o CNPq concedeu 134 bolsas, reflexo dos cortes de bolsas anunciados no início do segundo semestre de 2016 (PRÓ-REITORIA DE PESQUISA DA UNICAMP, 2016a). Para atender a demanda crescente pelo programa, a UNICAMP aumentou em $20 \%$ o número de bolsas para 2016 - 2017, somando 220 bolsas concedidas com recursos próprios (PRÓ-REITORIA DE PESQUISA DA UNICAMP, 2016b).

Nesse contexto, a pesquisa teve como objetivo analisar a contribuição do Programa na Universidade Estadual de Campinas 
(UNICAMP) no que tange a formação crítica dos estudantes do nível médio das escolas públicas no que diz respeito à ciência e cidadania. Para problematizar as possíveis relações entre ciência, cidadania e o Programa na UNICAMP, as experiências dos projetos desenvolvidos no Laboratório de Políticas Públicas e Planejamento Educacional (LaPPlanE) serviram de lócus para a busca do material utilizado na análise.

Apresentamos a seguir a compreensão que assumimos durante a pesquisa acerca dos conceitos de ciência e cidadania, bem como as atividades desenvolvidas nos projetos realizados dentro do LaPPlanE, e a partir daí estabelecemos relação dialógica entre essas atividades e a abordagem teórica, finalizando com algumas considerações vinculadas aos resultados da pesquisa.

\section{CIÊNCIA E CIDADANIA: nossos conceitos}

\subsection{Ciências ou Ciência?}

Para abordar o conceito de ciência adotamos como referência o autor português Boaventura de Sousa Santos que em seu livro Um Discurso Sobre as Ciências (2010) apresenta um apanhado histórico sobre a noção de ciência que se criou desde o século XVI, com o início da revolução científica, até o século XXI.

O autor trata do paradigma dominante, a nova ordem científica hegemônica, que teve início com o modelo de racionalidade seletivo entendendo que todo conhecimento que não fosse científico seria irracional e falso. Ele explica que, "o modelo de racionalidade que preside à ciência moderna constituiu-se a partir da revolução científica do século XVI e foi desenvolvido nos séculos seguintes basicamente no domínio das ciências naturais" (SANTOS, 2010, p. 10).

A Revolução Científica, que se inicia com os estudos de Einstein, se deu sob o domínio das ciências naturais sendo apenas no século XIX que ela se estende para as ciências sociais emergentes. 
A partir de então pode falar-se de um modelo global de racionalidade científica que admite variedade interna mas que se distingue $e$ defende, por via de fronteiras ostensivas $e$ ostensivamente policiadas, de duas formas de conhecimento não científico (e, portanto, irracional) potencialmente perturbadoras e intrusas: o senso comum e as chamadas humanidades ou estudos humanísticos (em que se incluíram, entre outros, os estudos históricos, filológicos, jurídicos, literários, filosóficos e teológicos) (SANTOS, 2010, p. 10).

A nova racionalidade científica nega o caráter racional de todas as formas de conhecimento que não se pautam em suas leis e princípios epistemológicos, acreditando que esse rigor é sinônimo de estabilidade e ordem. O paradigma dominante, o novo modelo de racionalidade e o rigor científico, desconfia das evidências humanas imediatas, fazendo uma rigorosa distinção entre o homem e a natureza.

Em primeiro lugar, conhecer significa quantificar [...] $\bigcirc$ que não é quantificável é cientificamente irrelevante. Em segundo lugar, o método científico assenta na redução da complexidade. O mundo é complicado e a mente humana não o pode compreender completamente (SANTOS, 2010, p. 15).

O conhecimento é tido como dominador e controlador da natureza, - racionalismo cartesiano prevalece com os princípios da mecânica newtoniana, que coloca que o mundo da matéria enquanto máquina pode ser controlado por meio de leis físicas e matemáticas. Assim, o paradigma dominante reconhece apenas duas formas de conhecimento: As disciplinas formais da lógica e da matemática e as ciências empíricas, nesta última incluidas as ciências sociais (SANTOS, 2010).

Neste sentido, as ciências sociais também ficam submetidas a tais leis que, de certa maneira, buscam uma forma de conhecimento utilitário e funcional. O paradigma dominante, da ciência moderna, preza por uma maior capacidade de dominar e transformar, do que pela capacidade de conhecer profundamente o real.

O autor aponta para uma crise do paradigma dominante e defende que: A crise é irreversível e profunda, estamos ainda em um período de revolução científica que não tem previsão para acabar e a única certeza 
que temos é que as principais características da nova ordem científica hegemônica entraram em colapso (SANTOS, 2010).

Para Santos (2010) há uma pluralidade de condições, sociais e teóricas, que favoreceram a crise do paradigma dominante. O paradigma científico moderno propiciou um grande avanço nas ciências que identificou os seus limites e as suas insuficiências estruturais, como o que aconteceu com a mecânica quântica:

Se Einstein relativizou o rigor das leis de Newton no domínio da astrofísica, a mecânica quântica fê-lo no domínio da microfísica. Heisenberg e Bohr demonstraram que não é possível observar ou medir um objecto sem interferir nele, sem o alterar, e a tal ponto que o objecto que sai de um processo de medição não é o mesmo que lá entrou (SANTOS, 2010, p. 25).

Os estudos da mecânica quântica de Heisenberg e Bohr fazem parte do grupo de condições teóricas que levaram à crise, porém a crise também se deu por condições sociológicas. Um exemplo é o fenômeno da industrialização da ciência, se num primeiro momento a ciência buscava um conhecimento desinteressado e autônomo, num segundo momento submeteu-se aos interesses econômicos, sociais e políticos de uma sociedade, os quais passaram a ter papel decisivo na definição das aplicações da ciência e na organização da investigação científica:

Quanto às aplicações, as bombas de Hiroshima e Nagasaki foram um sinal trágico, a princípio visto como acidental e fortuito, mas hoje, perante a catástrofe ecológica e o perigo do holocausto nuclear, cada vez mais visto como manifestação de um modo de produção da ciência inclinado a transformar acidentes em ocorrências sistemáticas (SANTOS, 2010, p. 35).

Já no que tange à organização do trabalho científico, a industrialização da ciência provocou alguns efeitos, como a estratificação da comunidade científica, tornando as relações entre os cientistas mais autoritárias e desiguais, e o fato de que "a esmagadora maioria dos cientistas foi submetida a um processo de proletarização no interior dos laboratórios e dos centros de investigação" (SANTOS, 2010, p. 35). Estes 
efeitos acarretaram no aumento do custo para se fazer ciência, tornando-se impossível o livre acesso à determinados equipamentos.

A crise trouxe à tona o paradigma emergente, que por sua vez vem acompanhado por quatro teses definidas por Santos (2010), são elas: 1) todo conhecimento científico-natural é científico-social; 2) todo o conhecimento é local e total; 3) todo o conhecimento é autoconhecimento; 4) todo o conhecimento científico visa constituir-se em senso comum.

Com a primeira tese o autor defende que com o surgimento deste novo paradigma deixa de fazer sentido a distinção entre as ciências naturais e sociais, colocando que: "Esta distinção assenta numa concepção mecanicista de matéria e da natureza a que contrapõe, com pressuposta evidência, os conceitos de ser humano, cultura e sociedade" (SANTOS, 2010, p. 37).

Recusando todas as formas de positivismo lógico, empírico ou mecanicista, as ciências sociais, com a revalorização dos estudos humanísticos, deveriam assumir a posição de catalisador das ciências (SANTOS, 2010). Ao falar de catalisador, o autor não se refere a uma ciência unificada e excludente, mas em um conhecimento que reconheça a importância dos conceitos, teorias, metáforas e analogias das ciências sociais.

Para Santos (2010), se observarmos o percorrer das ciências da natureza ficará nítido como fizeram uso de conceitos que presidem as ciências sociais. Tendo a Física percorrido um caminho no qual se apropriou das teorias e conceitos das ciências sociais, não faz mais sentido insistir nesta distinção entre as áreas do conhecimento. Trata-se de aceitar que as ciências estão interligadas, são teorias que fazem parte de um fenômeno não isolado.

A segunda tese, "todo conhecimento é local e total" parte do pressuposto de que a ciência moderna avança pela especialização, sendo o conhecimento mais rigoroso aquele que for o mais restrito possível sobre o seu objeto de análise. Porém, essa profunda especialização acarreta efeitos 
negativos impedindo uma formação mais ampla e complexa. A crítica que se faz é ao reducionismo arbitrário.

"No paradigma emergente o conhecimento é total, tem como horizonte a totalidade universal de que fala Wigner ou a totalidade indivisa de que fala Bohm" (SANTOS, 2010, p. 47). A ciência pós-moderna, ao contrário do que acontece no paradigma dominante, avança conforme o seu objeto de amplia; reconhecendo a complexidade da sociedade e, em especial, dos problemas sociais, compreende a incapacidade de lidar com eles de forma isolada, especializada, e passa a pensa-los numa perspectiva coletiva, onde as particularidades, quando juntas, darão conta da totalidade que passam a perceber e compor.

Quanto à terceira tese, "todo conhecimento é autoconhecimento", destaca-se característica do conhecimento científico que ensina a viver traduzindo-se em um saber prático, pois enriquece toda a nossa trajetória, sendo a prova mais intima daquilo que somos.

O autor explica que a distância epistemológica entre sujeito e objeto tem de ser articulada com a distância empírica que há entre eles. De acordo com Santos (2010), na antropologia, essa distância empírica era enorme, uma vez que o sujeito era o antropólogo europeu analisando o seu objeto: o outro povo primitivo tido como selvagem. Neste caso, metodologias foram adotadas para que a distância sujeito/objeto fosse encurtada a fim de que houvesse maior intimidade com o objeto de análise.

Situação bastante diferente aconteceu na sociologia, onde o europeu analisava o seu próprio povo. Nessa situação a distância epistemológica era mínima, fazendo com que o sociólogo adotasse metodologias de distanciamento para garantir um afastamento entre sujeito/objeto. Parafraseando Clausewitz, Santos (2010) destaca que hoje:

(...) o objecto é a continuação do sujeito por outros meios. Por isso, todo o conhecimento científico é autoconhecimento. A ciência não descobre, cria, e o acto criativo protagonizado por cada cientista e pela comunidade científica no seu conjunto tem de se conhecer intimamente antes que conheça o que com ele se conhece do real (p. 52). 
Sendo assim, os pressupostos que o cientista carrega com ele como suas crenças, valores e visões de mundo fazem parte da sua explicação científica da natureza e/ou da sociedade.

Por fim, a última tese aponta que todo conhecimento científico visa constituir-se em senso comum, fazendo uso do conhecimento que até então era tido como vulgar e ilusório. A ciência moderna acredita que o senso comum é prático e pragmático, desenvolvendo-se da trajetória e das experiências de vida de determinados grupos sociais, sendo transparente e evidente. O senso comum, para a ciência moderna, é indisciplinar e carece de método por ser o resultado de uma prática espontânea não orientada.

Segundo o paradigma emergente, são essas características que consagram a virtude antecipatória do senso comum e através desta virtude, acompanhada do conhecimento científico, é que uma nova racionalidade surgirá. A ciência pós-moderna busca adotar o conhecimento vulgar que todo ser humano carrega consigo, sendo parte integrante da produção do conhecimento científico.

É a partir de uma proposta de um paradigma emergente de ciência, fruto do reconhecimento de uma crise da racionalidade, que assumimos o que Santos (2010) entende por ciência. Uma ciência unificadora, dialógica, não dicotômica e deselitizada, com condições de vincular-se a um conceito de cidadania igualmente agregador, o qual discutimos a seguir.

\subsection{Por uma Cidadania no Brasil}

Para discutir a formação cidadã dos estudantes do nível médio é preciso identificar o que entendemos por cidadania; para isso utilizamos as contribuições teóricas do historiador José Murilo de Carvalho que em seu livro, Cidadania no Brasil - O longo caminho (2016). O autor não propõe um conceito, mas o apresenta como algo que vem sendo construído historicamente e que permanece em constante transformação, o que nos atraiu mais do que uma determinação acabada, haja vista ir ao encontro 
da própria proposta de Santos (2010) acerca da terceira tese "todo conhecimento é autoconhecimento".

Se é preciso superar a dicotomia sujeito/objeto, de forma que os objetos são distintas e possíveis continuidades do sujeito, falar do conceito de cidadania é, antes de mais nada, falar de cada um de nós, de forma que saber o que nos compõe, consequentemente, o que compõe a cidadania, torna-se mais importante do que poder dizer o que se é ao final, já que nesta lógica, sujeito é também objeto.

Nesse sentido, falando de cidadania - de nós - Carvalho (2016) destaca que no Brasil, com o fim da ditadura militar em 1985, o país enfrentou a labuta de (re)construção da democracia. Com a promulgação da Constituição Federal de 1988, conhecida como Constituição Cidadã25, o entusiasmo cívico culminou no equívoco de acreditar que o exercício de certos direitos levaria as pessoas a usufruírem de outros direitos ligeiramente.

O exercício de certos direitos, como a liberdade de pensamento e o voto, não gera automaticamente o gozo de outros, como a segurança e o emprego. O exercício do voto não garante a existência de governos atentos aos problemas básicos da população. Dito de outra maneira: a liberdade e a participação não levam automaticamente, ou rapidamente, à resolução de problemas sociais (CARVALHO, 2016, p. 14).

Passados vinte e oito anos da promulgação da Constituição Cidadã, o Brasil ainda enfrenta problemas centrais na sociedade como a violência urbana, o desemprego, a má qualidade dos sistemas públicos de saúde e educação, como também problemas de desigualdades sociais e econômicas. Como consequência do ritmo desacelerado das mudanças, o cidadão perde a confiança nos mecanismos e agentes do sistema democrático, como as eleições, o Congresso e os partidos (CARVALHO, 2016).

\footnotetext{
${ }^{25}$ A Constituição salienta, em seu artigo $1^{\circ}$, inciso II, que a República Federativa do Brasil união indissolúvel dos Estados e Municípios e do Distrito Federal - constitui-se como Estado Democrático de Direito e tem como principal fundamento a cidadania.
} 
A falta de perspectivas a curto prazo para tais problemas da sociedade, inclusive pela dependência do Brasil em relação a ordem econômica internacional, gera um clima de inquietação no país pelo sofrimento humano e pelo medo de soluções que signifiquem o retrocesso de longas conquistas.

Por esse motivo, Carvalho (2016) aponta a importância de uma reflexão sobre a cidadania em uma perspectiva histórica incluindo as suas várias dimensões. O autor brasileiro desdobra a cidadania em três direitos, a saber: os direitos civis, os direitos políticos e os direitos sociais.

O primeiro deles, os direitos civis, aparecem na Constituição no caput do artigo $5^{\circ}$ do Capítulo I que dispõe sobre os direitos e deveres individuais e coletivos. Tendo como pressuposto que todos são iguais perante a lei, os direitos civis são aqueles invioláveis que garantem o direito à vida, à liberdade, à igualdade, à segurança e à propriedade.

Os direitos civis se desdobram em mais de setenta incisos, tratando de temas como a igualdade entre homens e mulheres em direitos e obrigações, a livre manifestação do pensamento, a casa como asilo inviolável, a livre escolha de trabalho e o direito de ir e vir.

Com o desenvolvimento da sociedade capitalista, a existência da sociedade civil depende de relações civilizadas que são mantidas não só pela existência dos direitos civis, mas também pelo fato de que a garantia destes direitos se baseia em uma justiça, teoricamente, independente, eficiente, barata e acessível a todos (CARVALHO, 2016).

Já os direitos políticos, o segundo grupo de direitos que compõem a cidadania, apontam para a soberania popular através da participação do cidadão no governo da sociedade por meio do voto direto, sem mediações ou intermediações, e secreto. A conquista do voto direto aumentou a abrangência dos direitos políticos, uma vez que deu mesmo peso ao voto de cada indivíduo, possibilitando ao eleitor votar diretamente no candidato que escolheu para determinado cargo. 
No entanto, o voto no Brasil é um direito com exercício limitado, podendo ser facultativo para algumas parcelas da sociedade como para os analfabetos, maiores de setenta anos e os maiores de dezesseis e menores de dezoito anos (art. 14, CF/88).

Além do voto, os direitos políticos se desdobram nas demonstrações políticas e na organização de partidos. A cassação destes direitos é vedada e a perda ou suspensão só se dará nos casos especificados na legislação (art. 15, CF/88).

Por fim, temos o terceiro grupo, formado pelo os direitos sociais, quais sejam: "a educação, a saúde, a alimentação, o trabalho, a moradia, o transporte, o lazer, a segurança, a previdência social, a proteção à maternidade e a à infância, a assistência aos desamparados" (art. 6 , $\mathrm{CF} / 88)$.

Os direitos sociais garantem a participação na riqueza coletiva e a sua garantia se dá por meio da existência de uma máquina administrativa do Poder Executivo, buscando a diminuição das desigualdades sociais para garantir o mínimo de bem-estar (CARVALHO, 2016).

Tendo como base T. A. Marshall, Carvalho (2016) parte da ideia de que o desenvolvimento da cidadania se dá por meio de uma sequência lógica e cronológica, de forma que o cidadão pleno seria aquele titular dos três direitos, o incompleto seria titular apenas de um direito e o não cidadão não se beneficiaria de nenhum dos direitos. Nesta perspectiva, o autor aponta que é possível haver direitos civis sem direitos políticos, porém o contrário não é possível uma vez que sem a liberdade de opinião e organização, o direito ao voto fica esvaziado de sentido, servindo apenas para justificar governos. Já os direitos sociais, embora não dependa dos outros dois, sem eles, seu alcance e o seu conteúdo tendem a ser reduzidos a interesses específicos.

Um exemplo destas combinações de situações, e da consideração de cronologias e lógicas específicas, é a comparação do desenvolvimento da cidadania na Inglaterra e no Brasil. Na grande ilha, a cidadania se 
desenvolveu com muita lentidão, tendo no século XVIII a conquista dos direitos civis; no século XIX os direitos políticos e por fim, no século XX, os direitos sociais. Foi com base nas liberdades civis que os ingleses reivindicaram o direito ao voto e ao votar, eles elegeram operários que criaram o Partido Trabalhista, responsável por introduzir os direitos sociais.

Já no Brasil, o desenvolvimento e a constituição da cidadania seguiu uma outra cronologia. Primeiramente conquistamos os direitos sociais, implementados em um sinuoso período de supressão dos direitos políticos e de redução dos direitos civis por uma ditadura popular. Na Era Vargas (1930 - 1945) houveram grandes conquistas trabalhistas e sociais que culminaram na promulgação da Consolidação das Leis do Trabalho (CLT), influenciadas por correntes positivistas que se preservaram fieis ao pensamento de Augusto Comte: "No que se refere à questão social, Comte dizia que o principal objetivo da política moderna era incorporar o proletariado à sociedade por meio de medidas de proteção ao trabalhador e a sua família" (CARVALHO, 2016, p. 115).

Com a derrubada de Vargas em 1945, o Brasil retoma sua experiência democrática com a convocação das eleições presidenciais e legislativas em dezembro daquele ano. O período de 1945 - 1964 representou uma fase de grande participação e resistência da população brasileira, havendo a conquista dos direitos políticos, mas com o Golpe de Estado de 1964 o país enfrentou o início de um período de confrontos e o fim da democracia.

Foi só com a redemocratização do país, com o fim da ditadura militar, que a população voltou a construir e a conquistar os seus direitos civis garantidos então pela Constituição Federal de 1988. A situação estabelecida ainda é frágil, não só por considerarmos que o conceito está em constante transformação, mas em especial pela juventude democrática de nosso país, que sofre com perturbações causados nos âmbitos dos direitos políticos e civis. 
Considerando o conceito de ciência de Santos (2010) e a noção de cidadania discutida por Carvalho (2012), podemos dizer que o diálogo científico, entre as diferentes áreas do conhecimento, levará os indivíduos à ampliação de seus campos de discurso aumentando as chances de expandirem seus direitos civis, políticos e sociais enquanto cidadãos plenos. Essa relação é o ponto chave para a análise das atividades do Programa que será feita a seguir.

\section{AS EXPERIÊNCIAS NO LABORATÓRIO DE POLÍTICAS PÚBLICAS E PLANEJAMENTO EDUCACIONAL (LAPPLANE)}

O Laboratório de Políticas Públicas e Planejamento Educacional (LaPPlanE), da Faculdade de Educação (FE), recebeu nos últimos dois anos dez bolsistas do PIBIC-EM. Em 2014 o laboratório acolheu três bolsistas que participaram das atividades de pesquisa durante um ano no projeto "Judicialização do Direito à Educação"26. No ano seguinte, quatro bolsistas integraram o projeto "Ciência, Pesquisa e Cidadania"27; e neste ano, três bolsistas iniciaram suas atividades no segundo semestre no projeto "Pesquisa e Cidadania: Aprendendo com jogos, arte e ciência"28.

A pesquisa que aqui apresentamos, teve como lócus de busca de material os dois primeiros projetos desenvolvidos no LaPPlanE, por este motivo procuramos explicar a organização dos mesmos a fim de contextualizar tal experiência.

As atividades dos dois primeiros projetos foram vinculadas a um dos objetivos específicos da pesquisa interdisciplinar "Judicialização do Direito à

26 O projeto "Judicialização do Direito à Educação" teve início em agosto de 2014 e terminou em julho de 2015.

27 O projeto "Ciência, Pesquisa e Cidadania" teve início em agosto de 2015 e termino em julho de 2016.

28 O projeto em andamento "Pesquisa e Cidadania: Aprendendo com jogos, arte e ciência" iniciou-se em agosto de 2016 e tem previsão, segundo o calendário da PRP, para terminar em julho de 2017. 
Educação"29, a saber: consolidar o diálogo entre as ciências, primordial para compreender as políticas públicas educacionais, desenvolvendo conhecimento sobre a temática que envolve também uma convivência numa sociedade democrática.

Desta forma, o projeto contribui também com a formação do aluno no que tange a duas das finalidades do Ensino Médio previstas no artigo 35, incisos II e III da Lei $n^{\circ}$ 9.394/96 que estabelece as diretrizes e bases da educação nacional:

Art. 35: O ensino médio, etapa final da educação básica, com duração mínima de três anos, terá como finalidades:

(...)

II - a preparação básica para o trabalho e a cidadania do educando, para continuar aprendendo, de modo a ser capaz de se adaptar com flexibilidade a novas condições de ocupação ou aperfeiçoamento posteriores;

III - o aprimoramento do educando como pessoa humana, incluindo a formação ética e o desenvolvimento da autonomia intelectual e do pensamento crítico (BRASIL, 1996).

Com estes pressupostos o objetivo geral do trabalho com os estudantes bolsistas do PIBIC-EM era conhecer os possíveis diálogos entre as várias áreas do conhecimento, tendo como objetivos específicos identificálas, pesquisar as características marcantes das principais correntes de pesquisa e estabelecer relações dialógicas entre as áreas e as correntes de pesquisa com base no material levantado e nas leituras indicadas.

Os projetos previam atividades de pesquisa científica envolvendo fundamentação teórica e atividades fora da área acadêmica, a fim de desfrutar espaços de convivência que a Universidade oferece e que contribuem para a formação ética dos alunos, desenvolvendo autonomia intelectual e pensamento crítico dos mesmos.

Neste contexto apresentamos a seguir as atividades desenvolvidas nos projetos do PIBIC-EM no LaPPlanE entre 2014 e 2016.

\footnotetext{
29 A pesquisa em andamento tem como principal objetivo investigar as decisões do Tribunal de Justiça do Estado de São Paulo entre os anos de 1988 e 2013 com o propósito de reconhecer sua participação diante do controle de políticas públicas educacionais para a efetivação do direito à educação sob o Princípio da Dignidade da Pessoa Humana.
} 


\subsection{As atividades dos Projetos "Judicialização do Direito à Educação" e "Ciência, Pesquisa e Cidadania"}

No primeiro contato com os estudantes bolsistas era realizada sondagem, por meio de um questionário, para identificar seus lugares de fala. Com o questionário percebemos que a universidade se tornou para estes estudantes um lugar desconhecido e inalcançável, longe da realidade de cada um, no qual a principal e única atividade é a produção e a troca de conhecimento.

Os bolsistas chegavam com uma visão muito limitada sobre a UNICAMP e a FE, colocando em discussão a distância entre o Ensino Superior e a Educação Básica, que ainda persiste, interferindo nesta visão construída da universidade como algo inatingível. Sendo assim, apresentar a UNICAMP para os estudantes bolsistas era atividade de extrema importância, fazendose conhecer os aspectos de pesquisa, ensino e extensão enquanto indissociáveis (art. 207, CF/88) e formadores do tripé universitário.

Este primeiro contato com a UNICAMP foi estabelecido por meio de visita virtual e presencial ao campus de Campinas. Os encontros dos projetos aconteciam duas vezes por semana, de forma que um dia eram reservado para visitas presenciais nas diversas unidades e o outro para visitas virtuais.

Os estudantes conheceram os institutos do campus de Campinas, conhecendo um pouco mais sobre os cursos de graduação, visitando bibliotecas e laboratórios. Além disso, conheceram espaços de vivência como o Museu Exploratório de Ciências - UNICAMP30 e a Casa do Lago31.

Nas visitas virtuais, com a ajuda dos monitores, os bolsistas tiveram a oportunidade de conhecer os grupos de estudos e pesquisas das várias faculdades e institutos, bem como as propostas de intercâmbio oferecidas pela Vice-Reitoria de Relações Internacionais (VRERI) e as bolsas oferecidas pelo Serviço de Apoio ao Estudante (SAE).

\footnotetext{
30 https://www.mc.unicamp.br/

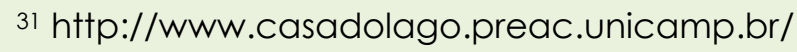


Ao final do mês de agosto, com o fim das visitas, os estudantes foram incentivados a refletir sobre a organização e a proposta da Universidade através de conversas que evidenciaram suas expectativas com a UNICAMP. Para encerrar essa primeira atividade eles produziram um mapa mental representativo no qual apresentaram a Universidade levando-se em conta tudo o que para eles foi significativo:

Figura 1: Mapa Mental produzido com as impressões dos alunos do PIBIC-EM no projeto "Ciência, Pesquisa e Cidadania"

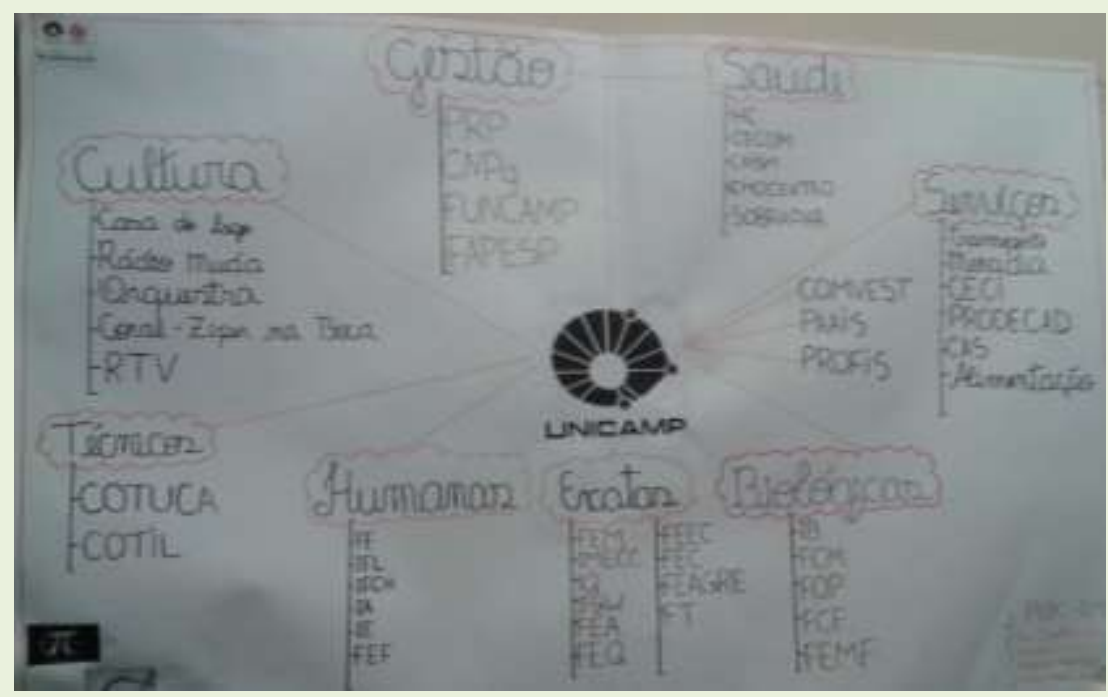

O mapa mental (BUZAN, 1994) é um diagrama voltado para a gestão de informações, trata-se de um método para planejamento e registro gráfico oriundo da socialização das ideias de todos os envolvidos no processo. Foi escolhido para o desenvolvimento da maioria das atividades do projeto por demandar trabalho coletivo dinâmico, de forma a aproximarse da realidade comunicativa dos jovens de hoje.

Os três meses seguintes foram dedicados a identificar a relação da universidade com as áreas e a produção do conhecimento através da leitura e discussão do livro "Um Discurso sobre as Ciências" (2010) do autor Boaventura de Sousa Santos.

Para trabalharem com o livro as atividades foram divididas em três momentos: 1. Leitura, 2. Discussão e 3. Mapa mental. 
Ao identificar o estranhamento e a dificuldade dos estudantes com a leitura do livro, julgou-se que seria crucial explorar as experiências de leitura dividindo o primeiro momento em dois. Em casa, os estudantes faziam uma leitura prévia do livro elaborando um glossário com as palavras que eles não conheciam ou que tinham dúvidas sobre o seu significado. Além disso, os estudantes arrolavam os vários autores citados no livro com o intuito de pesquisarem e conhecerem suas teorias e contribuições para a ciência.

A estratégia adotada favoreceu o entendimento do livro quando as leituras eram feitas em grande grupo nos encontros no laboratório. A leitura conjunta era feita em voz alta e cada membro do grupo ficava responsável por ler um trecho ou parágrafo do livro. Esta estratégia colaborou com o desenvolvimento dos estudantes no que diz respeito a desenvoltura na leitura e na comunicação.

Ao final das atividades com o livro de Santos (2010), os estudantes entregaram uma resenha individual na qual eles escolheram uma tese do paradigma emergente para discorrerem e relacionarem com situações do cotidiano de cada um. Com esta atividade os estudantes demonstraram que as teses se relacionavam com situações do cotidiano escolar e familiar, aderindo assim, significado a elas.

Podemos citar como exemplo a resenha em que o estudante escolheu a última tese, "todo conhecimento científico visa constituir-se em senso comum", para explicar e relacionar com situações do cotidiano familiar no qual alguns saberes eram passados de pai para filho sem nenhuma comprovação científica, sendo assim um conhecimento tido como vulgar. É como o chá de camomila para acalmar e aliviar o estresse que são receitas caseiras, passadas de geração para geração, sem decorrerem do rigor científico do paradigma dominante.

Após a entrega das resenhas individuais os estudantes se organizaram para elaborarem uma resenha coletiva, abordando os aspectos mais importantes do livro para eles. Foi uma atividade que uniu o grupo, mas que ainda assim trabalhou com as especificidades de cada um. As atividades 
coletivas, feitas em grandes grupos, foram essenciais para que os estudantes entendessem e respeitassem as caraterísticas e dificuldades de cada integrante dos projetos.

Com o fim das férias do final do ano os estudantes retomaram suas atividades em janeiro com o objetivo de pesquisar e conhecer as principais correntes de pesquisa estabelecendo uma relação destas com o processo de ensino-aprendizagem de cada aluno, em suas respectivas realidades, criando um diálogo entre as metodologias de pesquisa e as áreas do conhecimento.

Tal atividade teve como base o e-book "Metodologia do Trabalho Científico: Métodos e Técnicas da Pesquisa e do Trabalho Acadêmico" (PRODANOV \& FREITAS, 2013).

Foram incluídas nas atividades com o e-book uma roda de conversa com estudantes de graduação e pós-graduação que participaram de atividades de pesquisa. No período das atividades dos dois projetos receberam alunos da UNICAMP e da Universidade de São Paulo (USP). Além de compartilharem suas experiências, relatando as etapas de uma pesquisa cientifica, os estudantes convidados discutiram com os bolsistas questões sobre educação e o ensino superior.

Com o início do mês de fevereiro, os bolsistas PIBIC-EM concluíram o relatório parcial exigido pela PRP/UNICAMP, como forma de avaliação, que começou a ser elaborado antes das férias de dezembro. O relatório exigia a abordagem das atividades desenvolvidas entre agosto e fevereiro, sempre com o objetivo de entender como estas atividades contribuíram para a formação dos participantes.

Depois de entregarem o relatório parcial, os estudantes prosseguiram as atividades com os métodos de abordagem. Em um dia da semana havia a discussão sobre um método e no encontro seguinte a confecção de um mapa mental sobre o método de abordagem estudado naquela semana.

Com o fim dos métodos de abordagem iniciou-se a leitura dos métodos de procedimento e nessa etapa eles assumiram a responsabilidade 
de guiar os encontros. Em cada encontro um estudante ficava responsável por apresentar aos colegas uma aula sobre o método de procedimento escolhido. Os monitores incentivavam os bolsistas a utilizarem novos recursos para as apresentações, como a lousa, os computadores e o Datashow disponíveis nas salas de aula da Faculdade de Educação; além de incentivarem a utilização de outras linguagens de comunicação, como vídeos, dança, jogos e brincadeiras.

Para o método estatístico, por exemplo, eles organizaram uma pesquisa informal com os colegas da escola com o intuito de coletar dados para descobrir o número de estudantes do ensino médio que pretendem cursar o ensino superior. Já para o método experimental, a bolsista responsável pela apresentação organizou uma aula expositiva e ao final uma experiência prática envolvendo física e química. Para o método observacional, uma roda de conversa foi organizada para apresentar os conceitos teóricos do método e na sequência uma brincadeira de observação foi criada. Para fazerem a apresentação do método de procedimento um planejamento foi feito com o auxílio dos monitores para que cada um pudesse estudar e ensaiar sua apresentação. A orientação encaminhada para os estudantes foi de usarem a criatividade e o amplo referencial teórico disponível nas bibliotecas para o desafio posto.

Embora todas as atividades contribuíssem para o desenvolvimento da autonomia e da capacidade de lidar com situações fora do cotidiano, nesta etapa do projeto, tais ações se tornavam mais nítidas.

Com o fim da leitura do e-book iniciaram um novo ciclo de atividades com a Árvore de Problemas. Nesta etapa os bolsistas levantaram e socializaram problemas de ordem local em suas respectivas escolas para, a partir deles, discutirem e identificarem situações em que o diálogo científico entre as áreas dos conhecimentos, pudessem ajudar a buscar possíveis soluções.

A confecção da Árvore e a busca por possíveis soluções envolvia o uso de todas as disciplinas escolares presentes no currículo do nível médio da 
rede estadual paulista de ensino. Em uma destas atividades o problema levantado foi o uso constante de drogas ilícitas nas escolas e junto com a elaboração da Árvore uma roda de conversa sobre o assunto aconteceu no laboratório.

No mais, ao longo dos projetos, outras estratégias foram utilizadas para aproximação e discussão. Rodas de conversa com professores pesquisadores da UNICAMP e de outras instituições de ensino superior foram organizadas para discutirem questões referentes ao momento político e econômico que o Brasil vive atualmente. Além disso, criaram espaços de socialização e trocas de experiências com o caderno "Fica a Dica" e a página em uma rede social.

O caderno, que funciona como diário coletivo, guarda dicas e mensagens que os estudantes deixam como registro para os colegas. No "Fica a Dica" encontramos receitas de bolo, playlist, mensagens motivadoras, poemas e desenhos. Na página da rede social os estudantes compartilham suas experiências no projeto, como as atividades e as discussões.

Ao final de todas as atividades o calendário do projeto se encerra com a elaboração do relatório final, que abrange o que foi realizado de fevereiro até julho, e com a confecção do pôster a ser apresentado no Congresso de Iniciação Científica da UNICAMP.

O encerramento do projeto se dá por uma confraternização no LaPPlanE e ao final da semana por uma cerimônia formal organizada pela PRP/UNICAMP no Centro de Convenções da Universidade.

\section{O PIBIC-EM: a ciência e a cidadania}

Os estudantes bolsistas do Programa, oriundos da rede pública de ensino, carregavam com eles visões limitadas sobre a universidade e sobre a produção do conhecimento. Na sondagem feita no início das atividades de cada projeto observamos que os estudantes criavam uma relação entre a 
universidade e o "subir na vida", os bolsistas entendiam que a universidade era o espaço no qual o estudar levaria ao mercado de trabalho criando novas oportunidades para uma ascensão financeira. A universidade era tida como a melhor oportunidade de ter acesso ao conhecimento, exigindo de quem tivesse acesso a ela responsabilidade e comprometimento.

Além disso, as visões apresentadas por eles sobre a UNICAMP também eram limitadas. Os estudantes associavam primeiramente a Universidade ao Hospital das Clínicas, depois associavam mais uma vez à formação profissional voltada para o mercado de trabalho. Não havia o reconhecimento do tripé universitário nos aspectos de pesquisa, ensino e extensão. Uma das visões apresentadas colocava que a UNICAMP só receberia a comunidade externa para entretenimento.

Para falar de ciência os estudantes afirmavam que o conceito se referia ao estudo aprofundado sobre algo ou sobre alguma área, entendendo a ciência como o caminho para o conhecimento. Por fim, o conceito que apresentava o maior número de definições por eles é o de cidadania. A palavra era entendida como a ação de pensar individualmente, o saber conviver em sociedade e o ajudar ao próximo.

Não devemos desconsiderar as representações e assimilações por feitas pelos bolsistas, uma vez é resultado daquilo que são enquanto sujeitos históricos. A visão superficial sobre os conceitos também se deve ao fato de que, embora haja ampla discussão sobre ciência e cidadania, enquanto conceitos distintos, não podemos afirmar que ela seja crítica.

Como relatado, para que os estudantes conhecessem a Universidade, fazendo-se conhecer o seu tripé, as atividades tiveram início com as visitas virtuais e presenciais ao campus de Campinas. Conhecer e vivenciar a Universidade era essencial para que os estudantes entendessem que este espaço não se limita à produção sistematizada do conhecimento.

Entendemos que a universidade, assim como a escola e outras instâncias da sociedade, fazem parte do grupo de espaços propícios para que o indivíduo possa desfrutar e exercer sua cidadania, uma vez que instiga 
não só o conhecimento, mas também a conscientização política, social e cultural.

Enquanto estudantes do Ensino Médio, inseridos nos espaços da Universidade, os bolsistas do Programa tinham acesso aos espaços de convivência e de discussões políticas. Espaços estes que fazem parte daquilo que consideramos como espaços públicos, mas que mesmo sendo espaços da sociedade são pouco ocupados pela comunidade externa à UNICAMP.

Para ampliar a visão de Universidade, fazendo-se conhecer os diferentes espaços da Universidade, os estudantes participaram de atividades organizadas pelo Centro Acadêmico da Pedagogia. Uma destas atividades foi a Semana de Educação32 organizada todo ano pelos estudantes do curso de pedagogia e de licenciatura-integrada em química e física. A Semana de Educação propõe discussões que envolvem o contexto regional e nacional no que diz respeito à educação. Atividades são organizadas para discutir financiamento da educação, racismo, LGBTfobia, cotas raciais, arte e cultura.

As duas turmas de PIBIC-EM que desenvolveram atividades no LaPPlanE vivenciaram a Universidade em um contexto de greve. A primeira turma, do projeto "Judicialização do Direito à Educação", iniciou as suas atividades no contexto de greve e a última, do projeto "Ciência, Pesquisa e Cidadania", encerrou suas atividades em um período de greve na UNICAMP. Para que os estudantes entendessem o contexto das greves, rodas de conversa foram organizadas para discutirem as pautas de reinvindicações das três categorias (funcionários, estudantes e docentes).

A participação dos estudantes bolsistas do Programa nestas discussões, que envolvem questões de interesse da Universidade e da comunidade externa, auxiliou na ampliação das discussões sobre a convivência em uma sociedade democrática, o que consequentemente

32 Em 2014 os estudantes bolsistas participaram de algumas atividades da Semana de Educação que tinha como tema "Sem Grades" e em 2015 "Quem Educa a Pátria Educadora?". 
contribuiu para a conscientização do papel deles enquanto sujeitos de direito. Estas atividades resgatam a ideia de Morin (2012) de que a educação deveria se preocupar com a possibilidade de ensinar a compreensão. Essa compreensão, mútua e planetária, deve acontecer em todos os níveis educativos e em todas as idades. A compreensão é vital para que as relações humanas deixem o seu "estado bárbaro de incompreensão" (MORIN, 2012, p. 18).

Interessante destacar que a ação formativa dos projetos na perspectiva de Morin (2012) a fim de contornar a barbárie da incompreensão, vai ao encontro do que assumimos enquanto ciência e cidadania, já que este não pode se desenvolver sem aquele.

Disso decorre a necessidade de estudar as raízes e os efeitos da incompreensão, constituindo uma das bases mais seguras da educação para a cidadania, porque aborda temas como o racismo, explorando suas causas, não seus sintomas.

Com estes temas e nesta perspectiva, deixou de fazer sentido um conhecimento compartimentado, dando espaço para um conhecimento que fosse desenvolvido de uma maneira que possibilitasse o diálogo entre as diferentes áreas do conhecimento. Criando a possibilidade de tornar real aquilo que é apresentado por Morin (2012):

Torna-se necessário, portanto, promover a circulação de saberes que nos motivem a romper com a fragmentação do conhecimento que nosso modo de viver ocasiona. Trata-se da oportunidade de conduzir o homem a encontro consigo mesmo e em todas as suas dimensões, ou seja, da oportunidade de celebrar o encontro entre pessoa e natureza como expressões de uma única manifestação da vida, sem dicotomias e sem espaço para um existir predatório e desagregador (p. 11).

Os estudos feitos sobre as quatro teses do paradigma emergente que Santos (2010) pontuou foram feitas buscando uma aprendizagem significativa para que os bolsistas do Programa atribuíssem sentido e relacionassem todo o conhecimento com questões cotidianas da vida de cada um, por que não dizer, do exercício de cidadania de cada um. Ao 
conseguirem relacionar as teses com questões corriqueiras do cotidiano deles, foi possível entender que ciência não se limita ao conhecimento engessado produzido sistematicamente nas instituições de pesquisa e ensino superior. A produção do conhecimento deixou de ter como cenário principal a Universidade e passou a ser protagonista também em espaços como a escola, a comunidade e o lar.

Rompeu-se com a ideia de que a produção científica é um conhecimento único e acabado. A preocupação foi reconhecer as "cegueiras do conhecimento", as cegueiras da educação, que visa transmitir conhecimentos, em relação ao significado do que é o conhecimento humano. Isto é, a educação não se preocupa em fazer conhecer o que é conhecer. É necessário educar pensando no desenvolvimento das características cerebrais, mentais, culturais, dos conhecimentos humanos, de suas influencias psíquicas e culturais que o conduzem ao erro e à ilusão. Ademais, o desenvolvimento das ciências trouxe certezas, mas também uma zona de incertezas. A educação, para Morin (2012), deveria passar a incluir o ensino dessas incertezas que surgem nas ciências físicas, biológicas e históricas. Para o autor, "seria preciso ensinar princípios de estratégias que permitissem enfrentar os imprevistos, o inesperado e as incertezas" (MORIN, 2012, p. 17).

Nos relatórios enviados para a PRP/UNICAMP, ao final de cada semestre, ficou evidente como essa discussão marcou aquilo que eles entendiam por ciência, pesquisa e conhecimento. A criticidade ao tratar do assunto, produziu questões sobre o reconhecimento das incertezas do conhecimento e do diálogo entre as ciências como forma de promover a igualdade de oportunidades, uma característica da cidadania.

Deixou de fazer sentido para eles a valorização de certos saberes sobre outros, como a valorização da matemática e da língua portuguesa no currículo da Educação Básica deixando com carga horária reduzida disciplinas tão importantes quanto, como sociologia e filosofia. A solução 
encontrada por eles, foi a possibilidade de trabalhar tais conhecimentos de forma interdisciplinar prevalecendo a valorização de todas as áreas.

Também deixou de fazer sentido, a hierarquia produzida no campo científico daqueles que sabem menos e daqueles que sabem mais. Como colocado pelo educador brasileiro: "Não há saber mais, nem saber menos, há saberes diferentes" (FREIRE, 1987, p. 68).

Por fim, ainda com relação a formação cidadã dos bolsistas, o PIBICEM enquanto um programa que objetiva despertar a vocação científica abriu possibilidades para que os estudantes do nível médio de ensino fossem incentivados a dar continuidade à formação após a conclusão da Educação Básica. Os projetos incentivaram os estudantes a pensarem no ensino superior como uma das possibilidades, e não a única, de dar continuidade à formação. Ao instigar os bolsistas a pensarem sobre o futuro, os problemas locais nas escolas, as inquietações de toda uma sociedade fez com que eles desenvolvessem um pensamento crítico sobre o mundo.

\section{CONSIDERAÇÕES FINAIS}

Com base nos relatórios e nas atividades produzidas pelos estudantes tornou-se visível como estas discussões contribuíram significativamente para a formação deles. No que diz respeito ao pensamento crítico sobre a noção de ciência, percebemos que os estudantes passaram a questionar os caminhos e os resultados do conhecimento científico.

Já no que diz respeito ao reconhecimento do papel deles enquanto cidadãos foi impressionante a postura que assumiram como sujeitos capazes de reivindicarem seus direitos, enquanto estudantes da rede pública de ensino.

Neste caminho os estudantes passaram a assumir uma visão crítica sobre os problemas locais das escolas da rede estadual de ensino. Eles assumiram o papel de protagonistas pela reivindicação de melhorias na escola e em outros espaços também. O reconhecimento da educação 
como um direito social adquirido ao longo dos anos, por meio de muitas lutas, foi essencial para que eles assumissem a postura de protagonistas.

O reconhecimento da livre manifestação do pensamento e da igualdade entre homens e mulheres também foram essenciais para que os estudantes desenvolvessem conversas que despertaram discussões dialógicas. Enquanto sujeitos dotados de direitos políticos os estudantes passaram a assumir liderança em espaços de decisões.

A percepção daquilo que seria ciência e conhecimento, apresentada pela leitura do livro de Santos (2010), fez com o projeto acreditasse em uma produção científica que prezasse pelas relações de troca entre as diferentes áreas do conhecimento. Essa percepção que mantem a ideia de que não há distinção entre as áreas do conhecimento, que entende que a ciência nos ensina viver, que o conhecimento local também é total e que o senso comum constitui uma nova racionalidade científica, fez com os estudantes buscassem soluções para os problemas através do diálogo. Soluções que levassem em consideração as realidades locais e as possibilidades de criar e recriar o conhecimento.

Assumindo essas posturas os estudantes aumentam suas chances de ocuparem com sucesso os espaços nos quais desfrutarão da sua cidadania. É preciso conhecer, entender e lutar por aquilo que se acredita com bons argumentos. A ciência nos auxilia na busca por esses conhecimentos que servem de alicerce para os nossos argumentos.

A abordagem teórica utilizada para tratar de ciência foi o primeiro passo para que os estudantes envolvidos nas atividades de pesquisa caminhassem para o exercício pleno da cidadania. Retomando a ideia de Carvalho (2016), o cidadão pleno é aquele que consegue desfrutar dos seus direitos civis, políticos e sociais. Sabemos que muitos destes direitos são negados e negligenciados pelo Estado, porém, o projeto acredita que instigando o pensamento crítico sobre o mundo, os indivíduos cada vez mais estarão aptos a lutarem pela efetivação destes direitos. Desta forma o projeto aposta no diálogo entre as diferentes áreas do conhecimento como 
forma de exercer plenamente sua cidadania enquanto sujeitos de uma sociedade do saber.

\section{REFERÊNCIAS}

BRASIL. Lei de Diretrizes e Bases da Educação Nacional $n^{\circ}$ 9.394/1996. Disponível em: <http://www.planalto.gov.br/ccivil_03/leis/19394.htm> Acesso em: 12 novembro de 2015.

BRASIL. Constituição da República Federativa do Brasil de 1988. Disponível em:

<http://www.planalto.gov.br/ccivil_03/constituicao/constituicaocompilado.h tm> Acesso em: 12 novembro de 2016.

BUZAN, T. The mind map book. New York, USA: Dutton Adult, 1994.

CARVALHO, J. M. de. Cidadania no Brasil. O longo Caminho. $3^{a}$ ed. Rio de Janeiro: Civilização Brasileira, 2016.

CNPq - Bolsas por Quota no País. RN - 017/2006. Disponível em: <http://www.cnpq.br/web/guest/view/-

/journal_content/56_INSTANCE_OoED/10157/100352> Acesso em: 03 de julho de 2016.

FREIRE, P. Pedagogia do oprimido. $17^{\mathrm{a}}$ ed. Rio de Janeiro, Paz e Terra, 1987.

MORIN, E. Os sete saberes necessários à Educação do Futuro. São Paulo: Cortez, 2003.

PRODANOV, C. C.; FREITAS, E. C. de. Metodologia do Trabalho Científico: Métodos e Técnicas da Pesquisa e do Trabalho Acadêmico. $2^{a} e d$. Novo Hamburgo, RS: Feevale, 2013.

PRÓ-REITORIA DE PESQUISA DA UNICAMP. Comunicado Urgente PRP - PIBIC Redução de bolsas CNPq.11/08/2016. Disponível em: <https://www.prp.unicamp.br/pt-br/noticias/comunicado-urgente-prppibic-reducao-de-bolsas-cnpq> Acesso em: 30 Nov. 2016 a.

PRÓ-REITORIA DE PESQUISA DA UNICAMP. Documento com informações gerais do Programa Institucional de Bolsas de Iniciação Científica para o Ensino Médio (PIBIC-EM). Acesso restrito. Setembro, 2016b.

SANTOS, B. de S. Um Discurso sobre as Ciências. São Paulo, SP: Cortez, 2010.

Recebido em: Outubro de 2016 Aceito em: Dezembro de 2016 